\title{
Comments to "Usefulness of Doppler ultrasound-obtained resistance index in thyroid nodules with ultrasonographic malignant characteristics"
}

\author{
José Francisco Gallegos-Hernández \\ Instituto Mexicano del Seguro Social, Centro Médico Nacional Siglo XXI, Oncology Hospital, Ciudad de México, Mexico
}

\section{Gentlemen editors:}

I am sending this letter with the purpose to comment on the article "Usefulness of Doppler ultrasound-obtained resistance index in thyroid nodules with ultrasonographic malignant characteristics" by ButrónGarcía et al., published in Gaceta Médica de México 2018, volume 154, number 2, pages 161-164.

The purpose of the investigation described in the article was to know the value of ultrasound-determined resistance index of a thyroid nodule to identify thyroid cancer.

Although the title mentions "ultrasonographically suspicious nodules", this is not specified in the Method section, and neither are the ultrasonographic characteristics to consider them suspicious mentioned, which is an important aspect because if ultrasonographic findings would indicate the presence of suspicious nodules, knowing whether the resistance index by itself has a value that is independent to already known findings would be possible.

In addition, the authors do not specify if the correlation was made with the thyroidectomy product, i.e., whether all patients underwent surgery or if the gold standard was cytology obtained by fine needle aspiration biopsy, which is fundamental information because if the comparison is with cytology, the resistance index value is even lower since there would be no certainty of the true diagnosis.

Assuming that this comparison was made with the thyroidectomy product, it is important mentioning that this parameter (resistance index) had a false-positive index of $38 \%$ and false-negative of $10 \%$ in the series, so that more than one third of patients would no longer be punctured if the core needle biopsy was indicated only based on the nodule resistance index. Apparently, the true value of this ultrasonographic finding lies in that $86.6 \%$ of patients with a low index will not have thyroid cancer and, eventually, if there is no other ultrasonographic indication, ultrasound-guided core needle biopsy could be avoided in them.

The resistance index does not add any value to high-resolution ultrasound in thyroid nodules assessment and is currently not considered a parameter to be assessed in the ultrasound study of a thyroid gland tumor; the American Thyroid Association guidelines do not include it as a measurement or as a possible finding of risk for thyroid cancer; it does not allow indicating or ruling out puncture or surgery, which is the purpose of ultrasonographic evaluation of a thyroid nodule.

Accepted ultrasonographic findings that are closely related to the possibility of malignancy in solid hypoechoic or partially cystic thyroid nodules of $1 \mathrm{~cm}$ or more are irregular margins, microcalcifications, larger height than width, border calcifications with projection towards soft tissues and evidence of extrathyroid extension; their presence is considered of high risk for malignancy, with which between 70 and $90 \%$ are associated an thus constitute indications for puncture or thyroidectomy.

Since the resistance index has not an adequate relationship with histology, it cannot be considered an indicator for an invasive procedure in a thyroid nodule; even in nodules with low resistance index, it is the presence of some of the aforementioned high-risk findings that will indicate whether ultrasound-guided fine needle aspiration biopsy or surgical excision of the nodule should be performed.
Correspondence:

José Francisco Gallegos-Hernández

E-mail: jfgalh61@gmail.com
Date of reception: 13-05-2018

Date of acceptance: 21-05-2018

DOI://dx.doi.org/10.24875/GMM.M18000179
Gac Med Mex. 2018;154:424-424

Contents available at PubMed www.gacetamedicademexico.com 